\title{
DISCOVERY AND DESIGNATION OF TYPE SPECIMENS OF CHRYSOMELIDAE (COLEOPTERA) FROM ARGENTINA DESCRIBED BY E. VON HAROLD IN 1875.
}

\author{
By David G. Furth (1), Ingolf S. Askevold (2) \\ and Catherine N. Duckett (3)
}

\begin{abstract}
Type specimens of 14 species of Chrysomelidae from Cordova, Argentina, collected by W. M. Davis and described by E. von Harold in 1875, were discovered in the collections of the Museum of Comparative Zoology (Harvard University). A few specimens from some other museums such as the Museum für Naturkunde der Humboldt-Universität (Berlin), The Natural History Museum (London), Institut Royal des Sciences Naturelles de Belgique (Brussels), Museo Nacional de Hungaria (Budapest) are also apparently from the original series. Lectotypes and paralectotypes are designated for all species.
\end{abstract}

\section{INTRODUCTION}

In 1875 Edgar Baron von Harold published a paper on some Chrysomelidae from Cordova, Argentina which were sent to him from his friend Carl August Dohrn (Stettin), who had received them from Hermann Hagen (Cambridge). In this 1875 paper Harold listed 18 species from four chrysomelid subfamilies (Clytrinae, Eumolpinae, Chrysomelinae and Alticinae); 14 were described as new, including the new eumolpine genus Agrosterna.

It is not uncommon for the original type material of taxa described in the 19th century or before to be difficult to locate. It was fashionable then to exchange widely among collectors and museums and often type material was not indicated (labeled) as

(1) Department of Entomology, Museum of Comparative Zoology, Harvard University, Cambridge, MA 02138

(2) Entomology-Biological Control, Florida A. \& M. University, Tallahassee, FL 32307-2629

(3) Department of Biology, University of Puerto Rico, P. O. Box 23360, San Juan, PR 00931-3360

Manuscript received 23 December 1993. 
such; therefore, it is a significant contribution to insect systematics when such syntypical material is discovered. Although the Museum of Comparative Zoology (MCZ) at Harvard University has many types of Chrysomelidae, the vast majority of E. von Harold's types are located at the Museum für Naturkunde der Humboldt-Universität (Berlin) (Horn, 1926). The authors have discovered a quantity of specimens at the MCZ that we feel confident belong to the original specimens of taxa described by E. von Harold in 1875. The purpose of this paper is to designate lectotypes for these Harold taxa.

Below we often refer to institutions from which we have received specimens, information, etc. For the sake of brevity we will use the following abbreviations for these institutions, mostly following Arnett et al. (1993): ZMHB = Museum für Naturkunde der Humboldt-Universität, Berlin; ISNB = Institut Royal des Sciences Naturelles de Belgique, Brussels; HNHM = Hungarian Natural History Museum, Budapest; $\mathrm{MACN}=$ Museo Argentina de Ciencias Naturales, Buenos Aires; MCZB = Museum of Comparative Zoology, F. C. Bowditch Collection, Cambridge; $\mathrm{BMNH}=$ The Natural History Museum, London; ZSMC = Zoologisches Staatssammlung, Munich; MNHN = Museum National d'Histoire Naturelle, Paris; NHMS = Natural History Museum, Stettin (now incorporated into ZMPA); and ZMPA = Institute of Zoology, Polish Academy of Sciences, Warsaw.

\section{Museum of Comparative Zoology}

While curating the Neotropical Chrysomelidae at the Museum of Comparative Zoology (MCZ), the first author discovered a relatively large, folded, handwritten label alone on an insect pin that read: "16 Types ? of von Harold material coll. by Davis, sent by Hagen to Dohrn, sent by Dohrn to von Harold who published Col. Heft 14, 1875 p.95-106". The handwriting on this label is that of Nathan Banks (Curator of Insects at the MCZ from 1916-1945). The first and second authors searched the MCZ general collection and were able to locate all 18 taxa mentioned in Harold's 1875 paper. These specimens have machine-printed locality labels of three kinds: 1) all machine-printed as "Cordova. [top line] Argent.Davis [bottom line]"; 2) "Argent. [top line, machineprinted] Cord.Davis [bottom line, handwritten]", this is the most 
common kind; and 3) "Argentina: Cordoba W. M. Davis" (a square, white, machine-printed label with the country, city and collector name each on separate lines), there are very few specimens with this label. All of these taxa have the first specimen in the series bearing a handwritten determination (name) label apparently in the handwriting of Hermann Hagen. It is not clear why most series have two or three different kinds of locality labels.

Blake (1955) referred to the label about the " 16 types of Harold material collected by Davis...." (mentioned above) when discussing two species of Disonycha. For D. prolixa Harold, Blake assumed the type was in NHMS but implies that the MCZ specimens were sent to Dohrn and, although not labeled as types, were determined by Hagen as the Harold (1875) species and that they correspond well with Harold's original description. For D. caustica Harold, Blake assumed that the two MCZB specimens were the type and a paratype and eight other MCZ specimens were paratypes (= syntypes) (see comments for D. caustica below).

Hermann Hagen was the curator of insects at the MCZ beginning in 1867 and he had an active correspondence and exchange with C. A. Dohrn, a coleopterist in Stettin (Germany). The first author has reviewed C. A. Dohrn's letters to H. Hagen during the period from 1868-1880 (housed in the archives of the MCZ Library, Special Collections). Searching these letters for key words such as Cordova, Argentina, Davis, Harold, etc., there was little definitive mention of the specimens concerned here. There was only some discussion pertaining to the labeling system used by Hagen and his assistant (discussed below). However, Hagen (1874) indicates that the MCZ received these specimens in 1873 as a part of a larger collection of insects (dry and in alcohol) from Cordova which were presented to the MCZ by Mr. W. M. Davis. Between 1873-1875 there were other exchanges of foreign Coleoptera with C. A. Dohrn (Hagen, 1874, 1876, 1877). Hagen (1875) reported that in 1874 the Coleoptera from Cordova were arranged (= prepared and curated). Considering the very active exchanges at that time between Hagen and Dohrn, the chrysomelid specimens were apparently sent to Dohrn, and then, as the above-mentioned Banks label in the MCZ collection implies, they were forwarded by C. A. Dohrn to E. von Harold who subsequently described them. It remains unclear why only a few specimens of the original Cordova 
specimens remained in von Harold's collection (ZMHB) or elsewhere in Europe when the original series was returned to the MCZ.

In an 1876 letter to Hagen, Dohrn mentioned yellow-numbered labels and indicated that Hagen had been concerned about his (Hagen's) assistant mixing up some of the labeled specimens sent to Dohrn. From this letter it seems apparent that these yellow labels had been placed on the specimens in Cambridge. Also in this letter Dohrn seems to ask Hagen if there are more yellownumbered specimens and he seems to confirm that Hagen's assistant may have confused the numbering of the specimens that were sent to Dohrn. Some of the Cordova specimens in the MCZ collection do indeed have a yellow label with a number, i.e. 58, 61, 64, 66, 69. Also, some of the MCZ specimens have name labels (apparently written by Hagen) and some have other unclear labels (not Hagen written): "teste Dohrn also $=61 \mathrm{u}$. hamatifera", one of this same series has the yellow label number " 58 " mentioned above; one specimen of Urodera bergi has a handwritten label "Welche Numer ? Davis No=62"; a specimen of U. hamatifera has a label "Welche Numer? Davis No=61" and this specimen also has a yellow label with "61" but no locality label and is glued onto a rectangular card rather than pinned as are the other specimens; another Hagen label reads "Probably Ur. fallax Har. Dohrn sent as D. manca" [= Dachrys manca]. Several of the handwritten Hagen name labels have "Hagen determ." There is no apparent logical system to these various labels mentioned above. Probably the most important of these is that on $U$. fallax which indicates that Dohrn returned material to Hagen and that there was some confusion concerning the identity of this material.

The only common label in almost all cases is the locality label from Cordova, Argentina, Davis. Together with these same Cordova-labeled specimens in the MCZ we also found a few other species. Table 1 lists the number of specimens of the species from Harold (1875) in the various museum collections as well as the MCZ specimens of these other species.

Because the MCZ has the F. C. Bowditch Collection (MCZB) which contains the first and part of the second collections of Martin Jacoby, the first author also searched this for 1875 Harold species. The MCZB has identified specimens of 15 of the 18 Harold (1875) species, including a specimen of Stereoma burmeisteri with 
the following labels: "Cordova. Argent.Davis" (identical label to those mentioned above in the MCZ collection); "1st Jacoby Coll." (machine-printed); "Stereoma burmeisteri Harold" (handwritten). MCZB also had a specimen of Megalostomis histrionica with the same Cordova and Jacoby collection labels as on the previous specimen. Finally, an MCZB specimen of Disonycha caustica has a machine printed label "TYPE", a handwritten label "Cordova Davis", and a "1st Jacoby Coll." label.

\section{OTHER Museums}

According to Horn (1926), most of von Harold's private collection was deposited in the Museum für Naturkunde der Humboldt Universitat, Berlin and the Zoologisches Staatssammlung, Munich with a few possibly in the R. Oberthur Collection of the Museum National d'Histoire Naturelle (Paris). Dr. Fritz Hieke (Curator of Coleoptera) at the ZMHB was able to locate six specimens of five of the taxa from Harold's 1875 paper. These taxa and their labels are as follows: 1) "Urodera Bergi Har. typ" (handwritten), "Cordova. Argent.Davis" [machine-printed as in MCZ number 1 kind of label above]; 2) "Urodera fallax Har." (handwritten), "Cordova, Dohrn" [handwritten on green paper]; 3) "Coscinoptera tibialis Harold typ" (handwritten), "Cordova, Dohrn" [handwritten on green paper], "868." (machine-printed); 4) "Megalostomis histrionica Har. typ" (handwritten), "Cordova, Dohrn" [handwritten on green paper], "860." (machine-printed) [a second specimen of this species does not have a separate locality label, only a very different, handwritten label, on white paper with a green border "Cordoba, Megalostomis histrionica Har." and, thus, is clearly not from the type material]; 5) "Stereoma Burmeisteri Harold typ" (handwritten), "Cordova. Argent.Davis" [machine-printed as in MCZ number 1 kind of label above]; "872." (machine-printed). The handwritten scientific name labels were not written by Harold, it is not clear who wrote them. There are "Zool. Mus. Berlin" machineprinted labels on all six specimens. The third author visited the ZMHB and verified the above information as well as searching the ZMHB collections further and reviewing the archival records there for the Harold collection, especially type records. The specimens listed above were eventually sent to the first author for detailed examination. 
According to Dr. Gerhard Scherer (ZSMC) (in litt.) no specimens from the Harold (1875) paper are housed at his institution. Mlle. Nicole Berti (MNHN) (in litt.) located a label (no specimen present) "Cordova Diphaulaca cordovana typ Harold" and a specimen of Diphaulaca angularis labelled "typ". However, apparently neither of these labels was of the kind present in the MCZ or ZMHB collections.

The first author also contacted Mrs. Sharon Shute (BMNH) who was able to locate and send specimens of six of the new species described by Harold (1875); however, only one specimen of Megalostomis histrionica has an entirely machine-printed label ("Cordova. Argent.Davis" as in the MCZ collection). The other labels on this specimen are as follows: "SYN-TYPE" (white disk with an outer blue ring, normal BMNH syntype label); "Jacoby Coll. 1909-28a." (machine printed); "Megalostomis histrionica Harold" (handwritten).

Finally, we have contacted Dr. S. Adam Slipinski (ZMPA) because the collections of C. A. Dohrn as well as of his two sons Anton and Wolfgang, originally deposited in the Museum für Naturkunde, Stettin (MHNS) (Germany) (Horn and Kahle, 1935) were later transferred to ZMPA (Sachtleben, 1961). According to Slipinski (1985 and in litt.) most of the Chrysomelidae were either lost or destroyed by the end of the Second World War in 1945. In 1944 the Curator of Coleoptera of the Stettin Museum (Dr. R. Kleine) compiled a list of the types in that collection; however, types of only three of the 1875 Harold species of concern to the present paper were listed: Agrosterna buphthalma (Cotype); Diphaulaca cordovana (kind of type not specified); and Diphaulaca angularis (Cotype) (Slipinski, in litt.). There is no indication that the missing parts of the Stettin collection have been incorporated into other collections in Europe or Russia and, thus, no further information concerning these Stettin specimens is available (Slipinski, in litt.).

\section{DESIGNATION OF TyPeS}

It is quite clear that very few of the original specimens of the 18 taxa listed in Harold's 1875 paper, including syntypes or cotypes of the 14 new species, exist in any collection other than the MCZ. Therefore, we consider that there is strong evidence that the MCZ 
specimens represent the majority of the original material studied and described by Harold (1875) and that these specimens were returned to Hagen at the MCZ.

The status of several of the specimens discovered in European collections is actually not clear even though they have indications of "typ" ,"type", "cotype", or "syntype", because in the 19th and early 20th century the concept of types and type designation was quite different than today. In those times in original descriptions many authors did not indicate the number of specimens in the type series and did not designate holotypes. In addition, in former times specimens were often labeled with some version of the word type which often only meant that they were "typical" specimens. Below we refer to locality labels \#1, \#2 and \#3, which are explained at the beginning of the MCZ section above and at the end of Table 1 .

Although some of the evidence presented above is confusing and indicates that the type material examined by E. von Harold was not well marked, we feel that there is more than sufficient evidence to conclude that the specimens indicated by Nathan Banks as probable types are indeed from the original material studied by Harold. This material was certainly returned to $\mathrm{H}$. Hagen at the MCZ by C. A. Dohrn subsequent to Harold's 1875 paper even though Hagen was not completely certain of the identity of a few specimens. Hagen may have added his own handwritten scientific name labels based on correspondence either from Dohrn or from Harold (to Dohrn or to Hagen). Curators of other museums (BMNH, ZMHB, MNHN, and NHMS) felt confident enough of the status of some of these specimens to label some of this material (with the same printed Cordova, Davis labels) as syntypes or cotypes. Even though the present paper is not a taxonomic revision or monograph, there are not likely to be such taxonomic treatments involving these Neotropical taxa for quite some time (see Monrós, 1953, Blake, 1955, Moldenke, 1981). The first author has carefully examined and compared each specimen listed below to Harold's (1875) original description and all agree well. We feel that there is significant importance for the resolution of the type status of these specimens at this time. Therefore, we designate lectotypes and paralectotypes of the taxa described by Harold (1875) as follows: 


\section{CLYTRINAE:}

\section{Megalostomis histrionica Harold}

LECTOTYPE: (MCZ) male with \#2 locality label and a Hagen handwritten label "Megalostomis histrionica Harold n.sp. 88" [MCZ type \#33636].

PARALECTOTYPES: (MCZ) 5 males and 2 females with \#2 labels; 9 males and 4 females with \#1 labels; (MCZB) male with \#1 label and "1st Jacoby Coll." [all 21 MCZ \#33636]; (BMNH) male with \#1 label, "Jacoby Coll. 1909-21a", "SYNTYPE" [white disc with outer blue ring, and a handwritten name label; (ZMHB) male with "Cordova Dohrn" handwritten on green paper and "860", "Zool. Mus. Berlin" (machine-printed), "Megalostomis histrionica Har. typ" (handwritten on blue paper); (HNHM) 1 male \#1 label, "649" (machine-printed on yellow paper, "Megalostomis (Heterostomis) lacordairei Lac. F. Monrós det. 1951" (see also Monrós, 1953).

COMMENTS: According to Monrós (1953) M. histrionica is synonymous with $M$. lacordaire $i$ Lacordaire.

\section{Coscinoptera tibialis Harold}

LECTOTYPE: (MCZ) male with \#2 locality label [MCZ type \#33637].

PARALECTOTYPE: (MCZ) 1 male and 7 females with \#2 labels (one female with a Hagen-written label "Coscinoptera tibialis Harol., "95" (handwritten); 2 males and 3 females with \#1 labels [all 13 MCZ \#33637]; (ZMHB) female with "Cordova Dohrn" (handwritten on green paper), "868", "Zool. Mus. Berlin" (machine-printed), "Coscinoptera tibialis Harold typ" (handwritten on blue paper).

Dachrys gracilis Harold

LECTOTYPE: (MCZ) male with \#2 locality label, a Hagenwritten label "Dachrys gracilis Har. Hagen determ." [MCZ type \#33638].

PARALECTOTYPES: (MCZ) 4 males with \#2 labels and 3 males with \#3 labels [all $7 \mathrm{MCZ}$ \#33638].

COMMENTS: According to Monrós (1953) D. gracilis is a synonym of Temnodachrys aenofasciata (Lacordaire, 1848); this appears to be the establishment of this synonymy. Moldenke (1981) also places aeneofasciata in Temnodachrys. 
Dachrys manca Harold

LECTOTYPE: (MCZ) male with \#2 locality label, a Hagenwritten label: "Probably Dachrys manca Har." [MCZ type \#33639].

PARALECTOTYPES: (MCZ) 5 males and 3 females with \#2 labels; 1 male with \#1 label [all $9 \mathrm{MCZ} \# 33639$ ].

COMMENTS: According to Monrós (1953) this is Temnodachrys manca (Harold).

Stereoma burmeisteri Harold

LECTOTYPE: (MCZ) male with \#2 locality label [MCZ type \#33640]

PARALECTOTYPES: (MCZ) 2 males and 5 females (1 with Hagen-written label "Stereoma burmeisteri Harold 85") with \#2 labels; 1 female with \#1 label; (MCZB) 1 female with \#1 label and "1st Jacoby Coll." [all 9 MCZ \#33640]; (ZMHB) 1 female with \#1 label, "872", and "Zool. Mus. Berlin" (machineprinted), "Stereoma burmeisteri Harold typ" (handwritten on blue paper).

COMMENTS: According to Monrós (1953) S. burmeisteri is a subspecies of $S$. clitellata Lacordaire.

\section{Urodera bergi Harold}

LECTOTYPE: (MCZ) male with \#2 locality label and a Hagenwritten label "Urodera bergi *Har.", "90" (handwritten on white paper) [MCZ type \#33641].

PARALECTOTYPES: (MCZ) 6 males and 3 females with \#2 labels; 6 males and 4 females with \#1 labels [ 1 female also with a label "Welche Numer? Davis no=62"]; 1 female with \#3 label [all $20 \mathrm{MCZ}$ \#33641]; (ZMHB) 1 female with \#1 label, "Zool. Mus. Berlin" (machine-printed), "Urodera bergi Har. typ" (handwritten on blue paper).

COMMENTS: Monrós (1953) mentioned 1 example (ISNB) with a "Type" label. The first author examined 3 male specimens of this taxon sent from ISNB; 2 from the Duvivier collection with green, handwritten "Cordova, R. A. Davis" labels, and with machine printed "TYPE" labels; and 1 from the Chapuis collection with a white, handwritten "Cord. 90" label-these are not from the original series and, thus are not here designated as paralectotypes. 


\section{Urodera laevicollis Harold}

LECTOTYPE: (MCZ) male with \#2 locality label [MCZ type \#33642].

PARALECTOTYPES: (MCZ) 4 males (1 with Hagen-written label "Urodera laevicollis * Har.") and 5 females with \#2 labels; 1 male and 1 female with \#1 label [all 11 MCZ \#33642]; (HNHM) 1 male with \#1 label, "Stereoma laevicollis (Har.) F. Monrós det. 1951".

COMMENTS: According to Monrós (1953) U. laevicollis is in the genus Stereoma $(=S$. laevicollis laevicollis (Har.)). Monrós (1953) also mentioned 1 example (?sex), ?\# label from Cordova, collected by Davis (MACN); however, we were not able to receive this specimen for study.

\section{Urodera fallax Harold}

LECTOTYPE: (MCZ) male with \#2 locality label and a Hagenwritten label "Probably Ur. fallax Har. Dohrn sent as D. manca" [MCZ type \#33643].

PARALECTOTYPES: (MCZ) 7 males ( 1 also with a label "Welche Numer ? Davis no=66") and 4 females with \#1 labels; 7 males and 2 females with \#2 labels; 1 female with \#3 label [all 19 MCZ \#33643]; (ZMHB) 1 female with "Cordova Dohrn" (handwritten on green paper), "Zool. Mus. Berlin" (machineprinted), "Urodera fallax Har. typ" (handwritten on blue paper). COMMENTS: Monrós (1953) mentioned 2 examples (ISNB) with "R. A. Davis col." and "Urodera manca, Type" labels. Although these were not included in the material sent to us for examination, they are probably the same kind of labels as those mentioned above for $U$. bergi and, therefore, are also not part of the original series, thus, not designated as paralectotypes here.

\section{EUMOLPINAE:}

Colaspis maculipes Harold

LECTOTYPE: (MCZ) male with \#2 locality label and a Hagenwritten label "Colaspis maculipes Har. Hag. determ." [MCZ type \#33644]. There are no other known specimens.

\section{Agrosterna buphthalma Harold}

LECTOTYPE: (MCZ) male with \#2 locality label [MCZ type \#33645]. 
PARALECTOTYPES: (MCZ) 3 males and 1 female (also with a Hagen-written label "Agrosterna buphthalma Har. Hag. determ.") with \#2 labels [all $4 \mathrm{MCZ} \# 33645$ ].

\section{ALTICINAE:}

Diphaulaca cordovana Harold

LECTOTYPE: (MCZ) male with \#2 locality label [MCZ type \#33646].

PARALECTOTYPES: (MCZ) 1 male and 3 females with \#2 labels; 2 males and 3 females with \#1 labels [all 9 MCZ \#33646].

Diphaulaca angularis Harold

LECTOTYPE: (MCZ) male with \#2 locality label, a Hagenwritten name label "Diphaulaca angularis Har. 107." [MCZ type \#33647].

PARALECTOTYPES: (MCZ) 2 males and 3 females with \#2 labels; 1 male and 3 females with \#3 labels [all 9 MCZ \#33647].

Disonycha prolixa Harold

LECTOTYPE: (MCZ) female with \#2 locality label and a Hagen-written label "Disonycha prolixa Har. Hag. determ." [MCZ type \#33648].

PARALECTOTYPES: (MCZ) 2 females with \#2 labels; 1 female with \#3 label and a name label "Disonycha prolixa Harold DHB 1953" [=Doris H. Blake determined in 1953] [all 3 MCZ \#33648].

COMMENTS: Blake (1955) says that the type is "possibly at the Natural History Museum, Stettin, Germany.". Blake based this statement on written information from Dr. K. Delkeskamp (ZMHB). However, as stated above, the Stettin Museum type list does not indicate any material of this species in that collection and the Stettin Museum was transferred to ZMPA, but none of the Chrysomelidae from Harold (1875) is present at ZMPA.

\section{Disonycha caustica Harold}

LECTOTYPE: (MCZ) male with \#2 locality label and a Hagenwritten label "Disonycha caustica Har. 111" [MCZ type \#33649]. PARALECTOTYPES: (MCZ) 4 males and 2 females with \#2 labels; (MCZB) 1 female with an all handwritten locality label "Cordoba Davis", a machine-printed label "TYPE", and label "1st Jacoby Coll." [all 7 MCZ \#33649] 
Table 1. Original Cordova, Argentina, Davis specimens.

MCZ MCZB ZMHB BMNH HNHB

\section{CLYTRINAE:}

MCZ $M C Z B$ ZMHB BMNH HNHB

Megalostomis gazella Lacordaire

Megalostomis histrionica Harold

Coscinoptera tibialis Harold

Coscinoptera spp.

Dachrys aeneofasciata Lacordaire

Dachrys gracilis Harold

Dachrys manca Harold

Dachrys signatipennis Lacordaire

Dachrys sp.

Dachrys spp.

Stereoma burmeisteri Harold

Urodera bergi Harold

Urodera fallax Harold

Urodera hamatifera Lacordaire

Urodera laevicollis Harold

Urodera sp. near hamatifera

\section{9}

21

14

1

10

9

21

21

19

12

11

CRYPTOCEPHALINAE:

Cryptocephalus sp.

EUMOLPINAE:

Colaspis maculipes Harold

Agrosterna buphthalma Harold

CHRYSOMELINAE:

Plagiodera erythroptera Blanchard

\section{ALTICINAE:}

Cacoscelis melanoptera Germar 20

Diphaulaca angularis Harold $\quad 10$

Diphaulaca cordovana Harold 20

Diphaulaca sp.

Disonycha caustica Harold

Disonycha prolixa Harold

Caeporis coerulipennis Bryant
4

8

2

8

3

$\begin{array}{llll}1 & 1 & 1 & 1 \\ & 1 & & \\ & & & \\ & & & \\ & & & \\ & & & \\ & & & \\ & 1 & & \\ & 1 & & \\ & 1 & & \\ & & & \end{array}$

\section{1}

1

5

22

20
10
20
1
7
4
$11 *$

All specimens have printed labels as follows:

1) "Cordova, Argent. Davis" [all machine-printed];

2) "Argent., Cord. Davis" [last 2 words on bottom line are handwritten];

3) "Argentina, Cordoba, W. M. Davis" [all machine-printed].

Most taxa have mixed labels $=2$ or all three of the above kinds.

* these were mixed in with the series of D. cordovana Harold 
COMMENTS: Blake (1955) mentions that there is a female type (MCZB), a paratype and 8 other paratypes [= syntypes] in the general collection of the MCZ. She also states that "in the Bowditch collection are two others, evidently of the same series, the first labeled type, from Cordoba, Davis (2nd Jacoby collection), the second with the same label...". Blake (1955) basically says that there are 10 specimens: type and paratype (MCZB) and 8 others (MCZ); however, as indicated above, we have only found 7 (1 in MCZB and 6 in MCZ). However, we do not consider that Blake (1955) was designating these as lectotypes because she did not state this. Also, in her paper it is apparent that she only intended to list the type repositories for all species as she found them labeled or were reported to her from various museums.

\section{ACKNOWLEDGEMENTS}

The authors would like to thank the following for the loan of specimens and/or specimen information: N. Berti (MNHN); K. Desender (ISNB); F. Hieke (ZMHB); O. Merkl (HNHM); G. Scherer (ZSMC); S. Shute (BMNH); and S. A. Slipinski (ZMPA). We are also grateful to Dr. Curtis Sabrosky (Medford, NJ) for valuable advice. We would like to thank Ms. Britta Weimann (MCZ Library) for some German translation of C. A. Dohrn letters and Ms. Dana Fisher (MCZ Library, Special Collections) for help with the Dohrn letters. The second author's work was partially funded by an Ernst Mayr Grant from the MCZ and an NSERC Postdoctoral Fellowship. The third author was also partially funded by an Ernst Mayr Grant.

\section{REFERENCES}

Arnett, R. H., Jr., G. A. Samuelson, and G. M. Nishida. 1993. Insect and spider collections of the world. Second Edition. Sandhill Crane Press, Inc., Gainesville. $310 \mathrm{pp}$.

Blake, D. H. 1955. Revision of the vittate species of the chrysomelid beetle genus Disonycha from the Americas south of the United States. Proc. U. S. Nat. Mus. 104(3338): 1-86.

Hagen, H. A. 1874. Report on the Articulates. Ann. Rept. MCZ 1873, No. 200:16-19.

1875. Report on the Articulates. Ann. Rept. MCZ 1874, No. 75:12-17.

1876. Report on Insects. Ann. Rept. MCZ 1875, No. 10:18-20

1877. Report on Insects. Ann. Rept. MCZ 1876, No.5:21-23. 
Harold, E. von 1875. Über Chrysomelidae aus Cordova. Coleopterologische Hefte XIV:95-106.

Horn, W. 1926. Über den Verbleib der entomologischen Sammlungen der Welt. Supplementa Entomologica 12:1-133

Horn, W. and I. Kahle 1935. Über entomologische Sammlungen, Entomologen \& Entomo-Museologie. Entomologische Beihefte 2-4: 1-160.

Moldenke, A. R. 1981. A generic reclassification of the New World Clytrinae (Coleoptera: Chrysomelidae) with a description of new species. Ent. Arbeiten Mus. Frey 29:75-116.

Monrós, F. 1953. Revision sistematica de las especies de Clytrinae de la Argentina, Paraguay, Uruguay y Chile. Acta Zool. Lilloana 14:5-274.

Sachtleben, H. 1961. Nachträge zu "Walter Horn \& Ilse Kahle: Über entomologische Sammlungen". Beiträge zur Entomologie 11(5/6):481-540.

Slipinski, S. A. 1985. Stettin Museum Collection, Warsaw. Chrysomela No.12:2. 

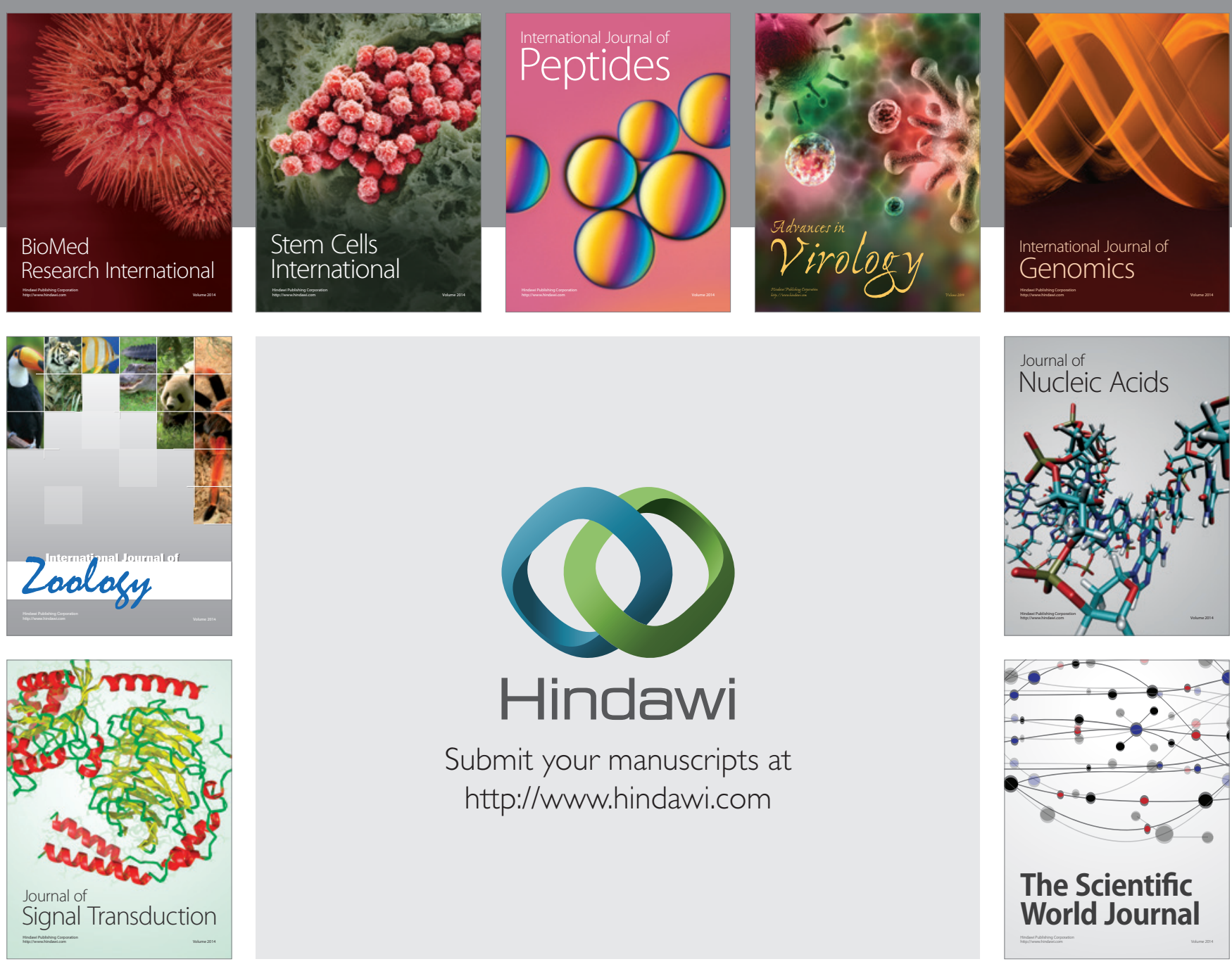

Submit your manuscripts at

http://www.hindawi.com
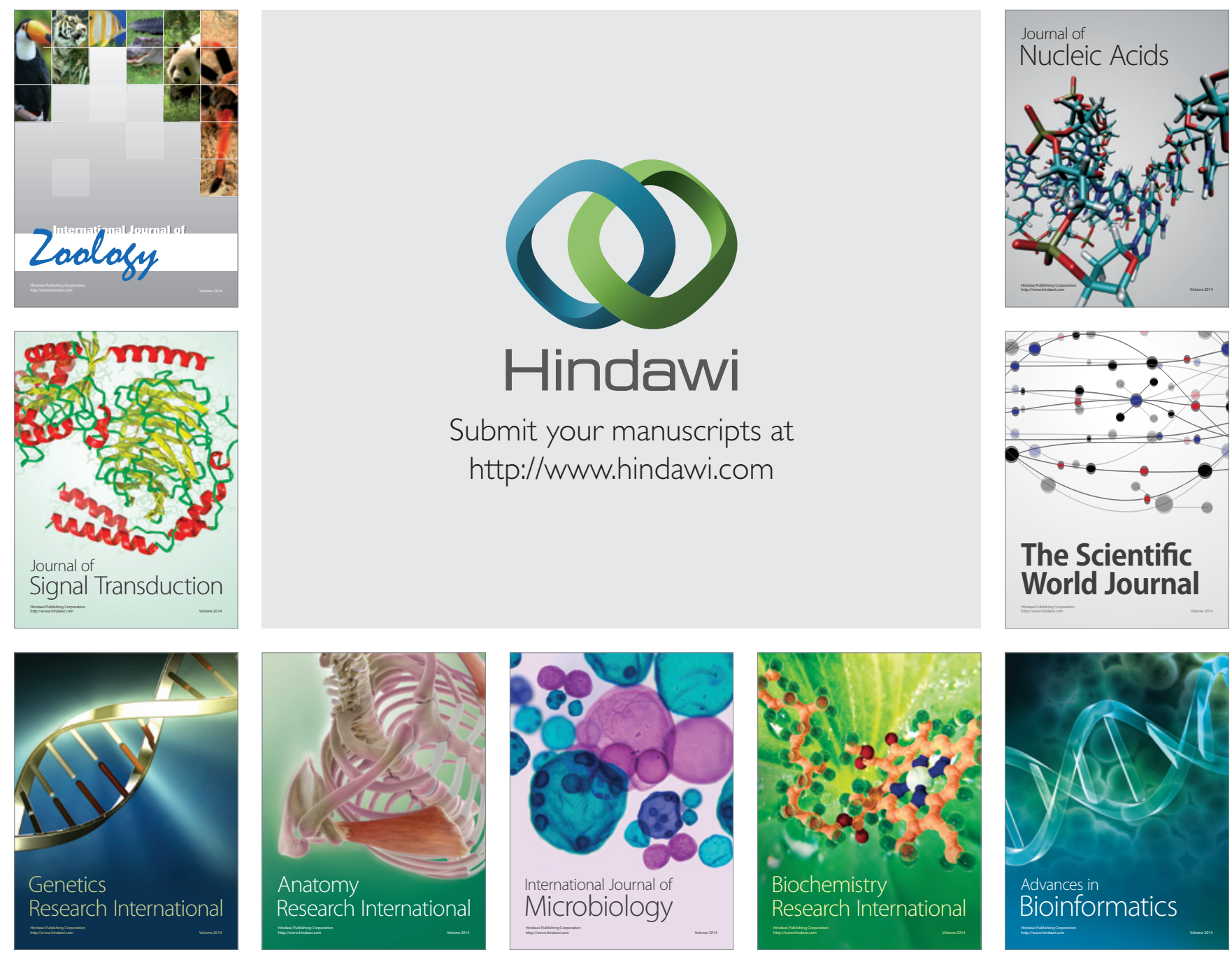

The Scientific World Journal
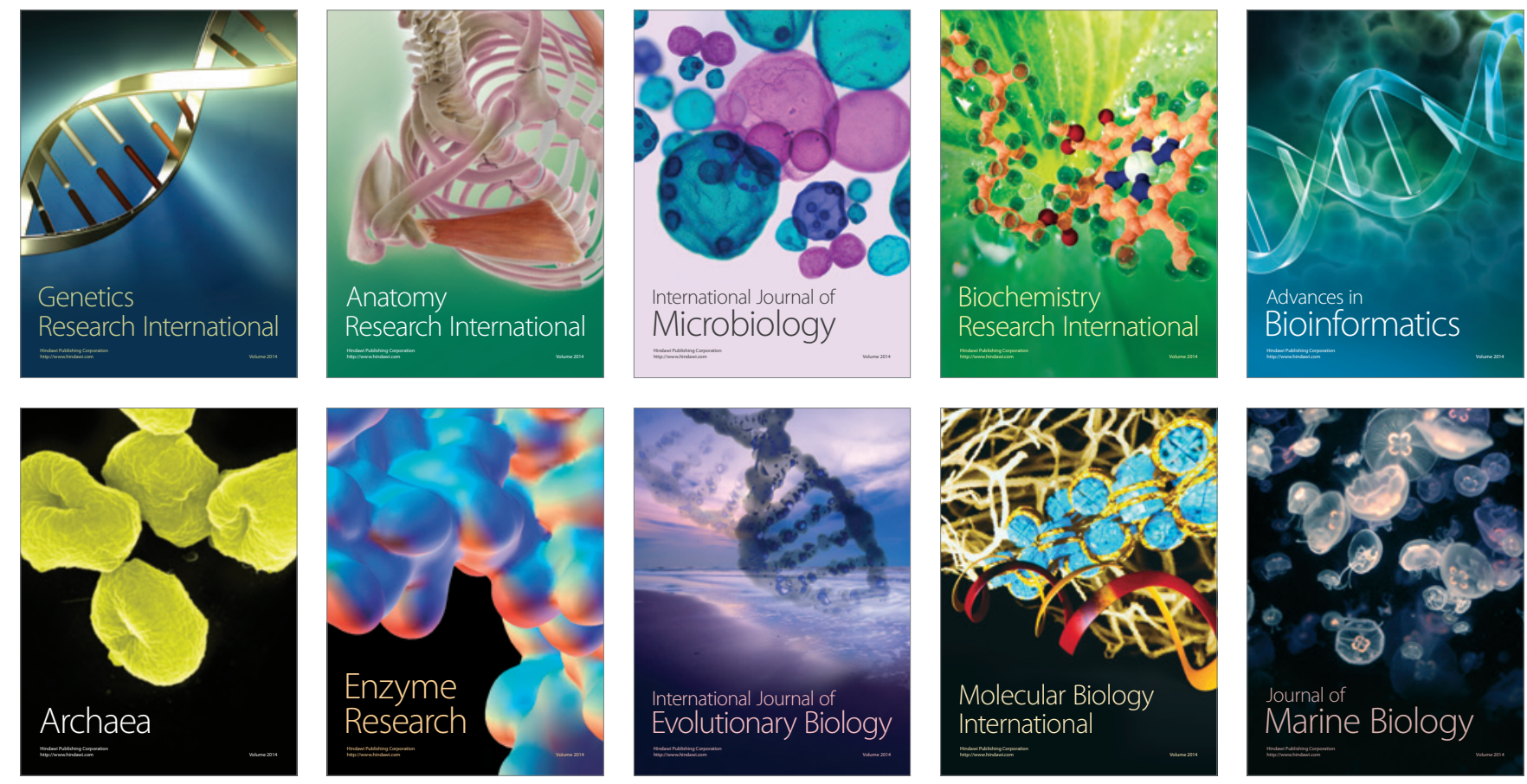